\title{
Teoria marxista e Buen Vivir
}

\author{
Marxist Theory and Buen Vivir
}

\section{Lorrany Rodrigues do Nascimento ${ }^{67}$}

\section{Resumo}

O objetivo do artigo é analisar as similitudes e as divergências entre duas concepções criticas ao capitalismo: a teoria marxista e o Buen Vivir, mais especificamente no que diz respeito às propostas de superação desse sistema e às condições para que elas se concretizem. As semelhanças evidenciam-se na oposição a um sistema caracterizado pela exploração do homem pelo homem e do homem pela natureza, pela produção exacerbada de mercadorias e pela ausência de sentido de um trabalho alienado. Ambas perspectivas propõem uma mudança que propicie a construção de uma sociedade menos desigual. Partem, entretanto, de entendimentos diferentes das condições para que essa mudança se concretize. Na teoria marxista, em que se tem por base o materialismo histórico, o comunismo só seria viável quando as relações de produção caracteristicas do capitalismo passassem a se constituir em um obstáculo ao desenvolvimento das forças produtivas e a exploração do proletariado pela burguesia atingisse o seu limite. Já no caso do Buen Vivir, a transformação social não teria como pressuposto o antagonismo de classe e a exploração, mas a noção de complementariedade e equilibrio; e a consciência não seria concebida como subordinada às condições materiais de existência, sendo o plano material e o plano simbólico, vistos como parte de um todo.

Palavras-chave: Buen Vivir. Teoria Marxista. Desenvolvimento. Comunismo.

\section{Abstract}

The article aims to analyze the similarities and the differences between two critical conceptions about the Capitalism: the Marxist Theory and the BuenVivir, more specifically considering the proposals to overcome this system and the conditions to materialize them. The similarities became clear with opposition to a system characterized by the exploitation of the men by the men and of the nature by the men, by the large production of commodities and by the loss of the meaning of an alienated work. Both perspectives propose changes that enable

${ }^{67}$ Bacharel em Sociologia pela Universidade de Brasilia (UnB) e Mestre em Sociologia pela Universidade Federal de Goiás (UFG). ORCID: 0000-0002-5764-8401. Email: lorranyrn@gmail.com. 
the construction of a less unequal society. Nevertheless, they are based in different understandings about the conditions to materialize it. In the Marxist Theory, based in the historical materialism, the Communism would be practicable only when the relations of production that characterize the capitalism configure an obstacle to the development of the productive forces and when the exploitation of the proletariat reach the limit. In BuenVivir, in its turn, the social transformation is not conditioned by the class struggle and the exploitation, but the ideas of complementary and equilibrium; and the conscious is not conceived as subordinate to the material conditions for the existence, inasmuch as the material and symbolic plane are not seen as separated.

Keywords: BuenVivir. Marxist Theory. Development. Communism.

\section{Introdução}

O artigo tem por objetivo fazer uma análise comparativa entre a teoria marxista e a concepção de Buen Vivir, que partem de uma perspectiva crítica em relação ao capitalismo. Entretanto, enquanto a primeira foi formulada a partir de uma perspectiva eurocêntrica, fundamentando-se na ideia de desenvolvimento e possuindo como herança iluminista a crença no progresso, o Buen Vivir consiste numa concepção elaborada por intelectuais latino-americanos que combina visões de mundo de povos andinos com teorias críticas ocidentais, propondo uma sociedade pautada na solidariedade e no comunitarismo.

A comparação entre essas duas correntes de pensamento já foi objeto de estudo por parte de outros autores, tal qual se evidencia na análise da obra de Cadermatori e Cadermatori (2013), em que é investigado o potencial de emancipação humana de ambas as teorias. Nesse trabalho, entretanto, tem-se como cerne a acepção prática do Buen Vivir, presente nas constituições do Equador e da Bolívia. Aqui, a ênfase será na perspectiva discursiva e ideológica presente na corrente pós-desenvolvimentista, tal qual será explicado posteriormente (CUBILLO-GUEVARA, 2014).

Conceituar o desenvolvimento demanda, primeiramente, a explicação de sua matriz: a ideia de progresso. Este pode ser associado à concepção de que o 
ser humano está em constante aperfeiçoamento (e não em decadência como se supunha na Idade Média) e de que amadurece no decorrer do tempo. Mais do que isso, a ideia de progresso impõe a escolha entre crescer constantemente ou perecer (HEIDEMANN, 2009; RIBEIRO, 2001). Essa noção se disseminou no contexto ocidental com o advento da modernidade (início do século XVI), sendo esta entendida como:

[...] um tipo de experiência vital - experiência de tempo e espaço, de si mesmo e dos outros, das possibilidades e perigos da vida que é compartilhada por homens e mulheres em todo o mundo, hoje. Designarei esse conjunto de experiências como "modernidade". Ser moderno é encontrar-se em um ambiente que promete aventura, poder, alegria, crescimento, autotransformação e transformação das coisas ao redor - mas ao mesmo tempo ameaça destruir tudo o que temos, tudo o que sabemos, tudo o que somos (BERMAN, 1986, p. 15)

A ideia de desenvolvimento passa a figurar em primeiro plano a partir da segunda fase da modernidade, no decorrer do século XIX. Ela se manifesta como uma forma mais concreta, operacionalizada, da crença no progresso, podendo ser definida como um discurso que divide a história humana em diferentes etapas, estágios evolutivos hierarquicamente dispostos, e que legitima a dominação de alguns países sobre outros por meio de sua pretensa neutralidade, expressa na concepção de que seria universalmente desejada (HEIDEMANN, 2009; RIBEIRO, 2001).

A teoria marxista tem por pano de fundo a ideia de desenvolvimento na medida em que formula uma concepção materialista e antropocêntrica da história. É de fundamental importância entender, para os propósitos desse artigo, que, apesar de estruturar sua teoria na crítica ao capitalismo e à distribuição desigual da riqueza socialmente produzida, Marx não se desvencilha de uma concepção linear e hierarquizada da história, entendendo que o comunismo só é passivel de se concretizar nos paises que apresentam um determinado grau de desenvolvimento das forças produtivas ${ }^{68}(\mathrm{RIBEIRO}, 2001)$.

\footnotetext{
${ }^{68}$ Fator em função do qual varia a quantidade de trabalho socialmente necessária para a produção de mercadorias e que depende, dentre outros fatores, "[d]o grau médio de habilidade dos trabalhadores, [d]o nivel de desenvolvimento da ciência e sua aplicabilidade tecnológica, [d]a combinação social do processo de produção, o volume e a eficácia dos meios de produção e as condições naturais" (MARX, 1996: 169).
} 
Contrapondo-se a essa ideia progressista de desenvolvimento e ao materialismo histórico, o Buen Vivir propõe uma concepção de mundo que vê o homem enquanto parte da natureza, considerando-a como sujeito de direito e não como um recurso, algo a ser transformado em prol da dominação. Segundo definição de Acosta:

El Buen Vivir, en definitiva, tiene que ver com otra forma de vida, con una serie de derechos y garantias sociales, económicas y ambientales. También está plasmado em los principios orientadores Del régimen económico, que se caracterizan por promover una relación armoniosa entre los seres humanos individual y colectivamente, así como com la Naturaleza. Em esencia busca construir una economía solidaria, altiempo que se recuperan varias soberanías como concepto central de la vida politica del país (ACOSTA, 2008, p. 38-9).

Assim, o Buen Vivir pode ser visto como uma alternativa à concepção de desenvolvimento, estruturando-se na ideia de complementariedade e equilibrio para a construção de uma sociedade mais igualitária e contrapondo-se à noção marxista que vê no antagonismo de classe o instrumento de mudança social. Esta última teoria, por sua vez, em decorrência do contexto em que é formulada, tem como pano de fundo a concepção eurocêntrica de desenvolvimento, característica da modernidade pós-iluminista, que vê no progresso, ao mesmo tempo, a tragédia e a possibilidade de redenção humana (BERMAN, 1986).

\section{Desenvolvimento e materialismo histórico}

O desenvolvimento evidencia-se dentro do pensamento marxista (sobretudo) em sua concepção materialista da história. Segundo esse autor, a sociedade passaria por diferentes estágios evolutivos, hierarquizados conforme o grau de desenvolvimento das forças produtivas, e superados na medida em que tais forças entrassem em contradição com as relações de produção (MARX, 2008). A transformação social, portanto, só se concretizaria com as mudanças das condições reais de existência, sendo a consciência vista, ao mesmo tempo, como uma emanação direta desta última e como o que possibilita a sua crítica e 
subversão (ENGELS; MARX, 2007; MARX, 2010).

No pensamento marxista, o que diferencia o ser humano dos animais é a intermediação, no seu contato com a natureza, da consciência, de uma capacidade de produzir sem que isso esteja vinculado ao suprimento de uma necessidade imediata. Seria através dela que o homem se tornaria capaz de pensar a si mesmo como parte de um grupo e como parte do meio em que se insere. Segundo Marx:

[...] Na elaboração do mundo objetivo lé que] o homem se confirma, em primeiro lugar e efetivamente, como ser genérico. Esta produção é a sua vida genérica operativa. Através dela a natureza aparece como a sua obra e a sua efetividade (Wirklichkeit). O objeto do trabalho é portanto a objetivação da vida genérica do homem: quando o homem se duplica não apenas na consciência, intelectual [mente], contemplando-se, por isso, a si mesmo num mundo criado por ele. (ENGELS; MARX, 2004, p. 85)

Assim, a natureza, originariamente, seria concebida como um corpo inorgânico, como um todo do qual o ser humano seria uma parte. Nesse momento, ela não se apresenta como um recurso, já que, não havendo divisão do trabalho, o homem tem ciência do processo produtivo, dos meios através dos quais pode suprir as suas necessidades com a transformação da natureza. Não há, ainda, alienação, estranhamento, apropriação do trabalho alheio e, portanto, a redução do meio ambiente à sua utilidade para o ser humano.

A partir do momento em que surge a propriedade privada, essa relação muda: tem início a primeira forma de divisão do trabalho, reservando-se o trabalho intelectual aos proprietários e o trabalho manual aos trabalhadores. A sociedade passa a ser dividida entre classes dominantes e classes dominadas e a exploração passa a impulsionar o antagonismo social.

Daí em diante, a natureza deixa de ser o meio no qual o ser humano se afirma por intermédio do trabalho e passa a ser um recurso a ser utilizado em benefício daqueles que detém os meios de dominá-la, transformá-la. Em outras palavras, os meios de produção (matérias-primas ${ }^{69}$, matérias auxiliares ${ }^{70}$ e meios

\footnotetext{
69"[...] Substância principal de um produto[...]" (MARX, 1996, p. 301).

70 Substância que entra no processo de fabricação da mercadoria para auxiliar sua fabricação, tal qual o carvão é utilizado para dar funcionamento à máquina a vapor (MARX, 1996, p. 301).
} 
de trabalho ${ }^{71}$ ) passam a ser controlados por uma classe específica e as outras classes, não tendo mais domínio do processo de produção daquilo que é necessário para sua própria subsistência, submetem-se à exploração (ENGELS; MARX, 2007).

À medida que a divisão do trabalho se intensifica e as desigualdades entre as classes se aprofundam, a dominação tornar-se-ia mais explícita e a contradição ficaria clara no plano da consciência. Nesse momento, seria possivel, então, a formação de uma consciência crítica, de uma filosofia que evidenciasse a exploração do homem pelo homem, capaz de unir as massas contra a classe detentora dos meios produtivos e de apresentar os interesses do segmento que pretende ter o controle desses meios como o interesse universal. Nos termos de Marx: "Para que um estamento seja par excellence o estamento da libertação é necessário, inversamente, que um outro estamento seja o estamento inequívoco da opressão" (MARX, 2010, p. 154).

Só depois da formação de uma consciência crítica e da disseminação desta entre as massas é que a transformação social se tornaria efetiva na forma da revolução e da reconfiguração da estrutura social. Por intermédio desse confronto físico, da luta de classes, é que um segmento deixaria de ser o detentor dos meios de produção e que a divisão do trabalho se transformaria. Em outras palavras, a luta de classes constituir-se-ia no motor da história, naquilo que impulsiona o desenvolvimento, a passagem de um estágio evolutivo a outro, transformando a relação dos homens entre si e com o meio no qual se inserem. Nos termos de Marx:

\begin{abstract}
A história nada mais é do que o suceder-se de gerações distintas em que cada uma delas explora os materiais, os capitais e as forças de produção a ela transmitidas pelas gerações anteriores; portanto, por um lado ela continua a atividade anterior sob condições totalmente alteradas e, por outro, modifica com uma atividade completamente diferente as antigas condições [...]. (ENGELS; MARX, 2007, p. 40)
\end{abstract}

Essa história só passaria a ter um caráter universal com o advento do modo

\footnotetext{
${ }^{71}$ Objetos que intermedeiam a relação do trabalhador com o seu objeto de trabalho, tais quais as ferramentas e as máquinas (MARX, 1996, p. 298).
} 
de produção capitalista, quando o intercâmbio entre as nações se intensificasse e se estabelecesse o mercado mundial (ENGEL; MARX, 2007). A partir desse momento, as inovações tecnológicas tornar-se-iam cada vez mais recorrentes e a divisão do trabalho mais intensa, gerando um grau de alienação cada vez maior do trabalhador e, consequentemente, uma crescente incapacidade deste indivíduo de se identificar com a natureza e com os outros seres humanos.

A degradação do trabalhador se tornaria tão insuportável, que sobre ele recairia todo tipo de opressão, de injustiça social. Ele não teria nenhum privilégio a ser assegurado, nenhuma propriedade a ser preservada, constituindo-se, portanto, na negação de todas as classes. À medida que essa exploração se intensificasse e a dominação ficasse mais evidente no plano da consciência, o proletariado (trabalhadores da grande indústria) teria condições, então, de se organizar e, assim, alcançar a sua emancipação (MARX, 2010).

Essa emancipação, desse modo, teria como requisito o fim da exploração do homem pelo homem, a não concentração dos meios de produção nas mãos de uma classe específica, ou seja, o fim da propriedade privada e da divisão da sociedade em segmentos com interesses antagônicos. Isso se concretizaria por meio da revolução, que, em sua última instância, manifestar-se-ia na sociedade comunista, onde a divisão do trabalho, e consequentemente, o estranhamento do homem em relação à natureza e em relação a si mesmo teria fim. Segundo Marx:

[...] A divisão do trabalho nos oferece de pronto o primeiro exemplo de que, enquanto os homens se encontram na sociedade natural e, portanto, enquanto há a separação entre interesse particular e interesse comum, enquanto a atividade, por consequência, está dividida não de forma voluntária, mas de forma natural, a própria ação do homem torna-se um poder que the é estranho e que a ele é contraposto, um poder que subjuga o homem em vez de ser por este ser dominado. Logo que o trabalho começa a ser distribuído, cada um passa a ter um campo de atividade exclusivo e determinado, que lhe é imposto e ao qual não pode escapar; o indivíduo é caçador, pescador, pastor ou crítico, e assim deve permanecer se não quiser perder seu meio de vida - ao passo que, na sociedade comunista, onde cada um não tem um campo de atividade exclusivo, mas pode aperfeiçoar-se em todos os ramos que the agradam, a sociedade regula a produção geral e me confere, assim, a possibilidade de hoje fazer isto, amanhã aquilo, de caçar pela manhã, pescar à tarde, à noite dedicar-me à criação de gado, criticar após o jantar, exatamente de acordo com 
a minha vontade, sem que eu jamais me torne caçador, pescador, pastor ou critico (ENGELS; MARX, 2007, p. 37-8).

Nesse ponto da teoria marxista, torna-se mais clara a concepção de desenvolvimento enquanto uma visão de mundo eurocêntrica e hierarquizante. 0 mercado mundial faria com que todos os povos do mundo fossem arrastados em uma direção especifica de desenvolvimento: o capitalismo. É ele que, tendo em

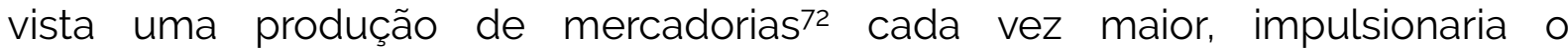
desenvolvimento tecnológico e, consequentemente, a menor suscetibilidade do homem aos infortúnios da natureza.

O comunismo, a projeção de Marx de uma sociedade menos desigual e na qual o homem reestabelece a ligação com seu corpo inorgânico e com os outros homens, só se materializaria depois que a humanidade evoluísse, que passasse por uma série de etapas históricas, bem definidas e cronologicamente hierarquizadas, superadas através da luta entre as classes sociais. Assim, paradoxalmente, o desenvolvimento aparece, dentro da teoria marxista como algo que aliena, degrada e divide os homens, mas também como o movimento, a marcha, que possibilita, através da transformação das suas condições reais de existência, a sua emancipação.

Desse modo, na teoria marxista, o desenvolvimento promovido pela sociedade e economia burguesa são exaltados, sendo relacionados a grandes avanços tecnológicos e transformações. Marx não se opõe ao desenvolvimento em si, já que deposita no seu dinamismo a chave para a superação do sistema capitalista. O que se apresenta como prejudicial dentro do pensamento marxista é a distorção que esse desenvolvimento sofre quando subordinado aos propósitos do capital, já que, nessas condições, passaria a entravar o autodesenvolvimento humano sob a forma da exploração (BERMAN, 1986).

72Forma elementar de riqueza dentro da sociedade capitalista (MARX, 1996). 


\section{O Buen Vivir}

O Buen Vivir é uma visão de mundo em permanente construção, que combina a descolonização dos saberes com o respeito da diversidade cultural, tendo por fonte tanto a cosmovisão de povos andinos quanto as teorias produzidas dentro do ocidente que criticam a modernidade (GUDYNAS, 2011). Tem como fundamento a noção de que o ser humano é uma parte da natureza, sendo necessária uma relação de complementariedade e equilibrio entre todas as formas de existência para que seja possivel uma vida plena.

Cubillo-Guevara et al (2014) elaboraram uma tipologia do Buen Vivir na qual esta concepção é dividida em três correntes de pensamento distintas: a Indigenista (que tem como referência principal Pablo Dávalos), a Socialista (em que tem maior destaque o trabalho de René Ramírez) e a Pós-desenvolvimentista (na qual se dá maior ênfase ao trabalho de Alberto Acosta). Neste artigo, a corrente a ser utilizada corresponde à Pós-desenvolvimentista, que parte do entendimento de que as verdades vistas como universais podem ser rejeitadas adotando-se como referência uma perspectiva Pós-modernista73. Seria a adoção desta referência que possibilitaria a busca de alternativas ao mal desarrollo ${ }^{74}$ específicas a cada território e, assim, a implementação do Buen Vivir.

Dentro dessa corrente, o Buen Vivir pode ser abordado a partir da perspectiva ideológica, discursiva ou prática. Essa última acepção tem ganhado maior atenção nas duas últimas décadas devido ao papel, enquanto eixo orientador, que exerceu sobre as constituições da Bolivia e do Equador. Entretanto, aqui, o foco será dado às suas acepções ideológicas e discursivas, ou seja, à crítica que faz ao desenvolvimento e aos processos por meio dos quais

\footnotetext{
73 "Simplificando ao extremo, considera-se "pós-moderna" a incredulidade em relação aos metarrelatos. É, sem dúvida, um efeito do progresso das ciências; mas este progresso, por sua vez, a supõe. Ao desuso do dispositivo metanarrativo de legitimação corresponde sobretudo a crise da filosofia metafísica e da instituição universitária que dela dependia. A função narrativa perde seus atores (functeurs), os grandes heróis, os grandes perigos, os grandes périplos e o grande objetivo. Ela se dispersa em nuvens de elementos de linguagem narrativos, mas também denotativos, prescritivos, descritivos etc., cada um veiculando consigo validades pragmáticas sui generis" (LYOTARD, 2009).

74 Entendido como uma metáfora que permite associar a noção de desenvolvimento elaborada no contexto da modernidade ao desequilibrio, à "[...] insatisfação de necessidades humanas básicas", associadas, por sua vez, não só a variáveis econômicas, mas ao direito à liberdade, identidade e segurança (TORTOSA, 2009, p. 21).
} 
essa concepção é legitimada (GUDYNAS, 2011).

Desse modo, as considerações feitas acerca do Buen Vivir nesse trabalho constituem-se em uma síntese, uma simplificação incapaz de abarcar todos os sentidos que esse termo possui e toda a sua complexidade. Entretanto, tendo em vista que o objetivo é apresentá-lo enquanto uma alternativa à concepção ocidental de desenvolvimento (mais precisamente ao modo como é aplicada dentro da teoria marxista), pode-se apontar os principais aspectos por meio dos quais se opõe a essa noção.

O primeiro aspecto a ser discutido aqui é o materialismo. Na teoria marxista a consciência é um reflexo da vida material, sendo necessário que nesta se instaure uma série de contradições entre os segmentos sociais para que aquela se converta em instrumento de mudança. Além da capacidade de transformação social, o próprio surgimento da consciência é visto como condicionado pelas condições materiais de existência, só se efetivando na medida em que se manifesta através do trabalho, da agência sobre a natureza sem que se tenha por objetivo a satisfação de uma necessidade imediata.

No Buen Vivir, o plano material não é visto como separado da consciência, não se tem por matriz a dualidade cartesiana corpo/mente e nem a natureza é vista como externa ao homem. A religião, a organização social e as representações simbólicas não são tidas como uma emanação direta das condições materiais de existência, como construções que reproduzem os interesses da classe dominante e geram alienação. O plano simbólico e o plano material são concebidos como partes de um todo, mas não são alocados dentro deste hierarquicamente, de modo que a transformação do primeiro se reduza a um reflexo da transformação do segundo.

Nesse ponto, é importante mencionar o papel desse distanciamento em relação à concepção materialista da história para romper com o eurocentrismo, sistema de poder que relega os saberes que não são produzidos sob a lógica europeia ocidental a uma posição de inferioridade, convertendo-se em um instrumento de legitimação do poder. A partir dessa lógica, a Europa fundamenta a sua dominação sobre outros povos, categorizando o conhecimento que dela 
escapa como irracional (QUIJANO, 2005).

Ao atribuir centralidade às cosmovisões que são relegadas a uma posição de inferioridade, o Buen Vivir quebra a hierarquia, promovendo a decolonialidade do saber. Esta é definida por Gudynas como:

[...] reconocer, respetar e incluso aprovechar, la diversidad de saberes. Se rompe (o se intenta romper) com las relaciones de poder dominantes, abandonándose la pretensión de un saber privilegiado que debe dominar y encauzar el encuentro de las culturas y saberes. Esto es más que un relativismo epistemológico, ya que se recuestaen una descolonización Del conocimiento. Los demás saberes se vuelven legítimos, y consecuentemente se debe reconfigurar la dinámica política para lidiar com ellos." (GUDYNAS, 2011, p. 15)

No mesmo sentido, ao romper com a ideia de que haveria uma separação entre o ser humano e a natureza, ele distancia-se da ideia de que existiriam raças mais propensas ao uso da racionalidade e raças mais instintivas, próximas à natureza e menos propensas à civilização (QUIJANO, 2012).

Outro contraponto à teoria marxista é o questionamento da ideia de desenvolvimento econômico disposto em uma trajetória linear. A vida plena, dentro do marxismo, só é alcançada na sociedade comunista, quando o homem se emancipa das vicissitudes naturais e da dominação de outros homens. O estranhamento só é abolido depois que o ser humano, por meio do desenvolvimento dos meios de produção, se torna capaz de submeter a natureza aos seus propósitos e tem sua consciência transformada pelas revoluções sociais impulsionadas pelas lutas de classes.

No Buen Vivir não há um ideal comum de desenvolvimento a ser seguido e não há o objetivo de, necessariamente, se chegar a uma sociedade comunista. Cada povo, a partir de sua própria visão de mundo, crenças, costumes e estilo de vida, deve elaborar sua estratégia de futuro (CUBILLO-GUEVARA et al, 2014). Segundo Acosta:

Bajo algunos saberes indígenas no existe uma idea análoga a la de desarrollo, lo que lleva a que em muchos casos se rechace esa idea, No existe la concepción de um proceso lineal de la vida que establezca um estado anterior e posterior, a saber, de subdesarrollo e desarrollo; dicotomía por la que debentranstarlas personas para la consecución del bien estar como ocurre em el mundo occidental. Tampoco existen conceptos de riqueza e 
pobreza determinados por laacumulación y lacarencia de bienesmateriales" (ACOSTA, 2015, p. 310).

Estabelece-se, assim, um contraponto não só ao ideal de desenvolvimento marxista, mas àquele hegemônico desde o pós-guerra, que tem como cerne a divisão do mundo entre países desenvolvidos e subdesenvolvidos, sendo a posição desfavorável destes dentro do processo de acumulação do capital justificada pela ideia de atraso, assim como a interferência externa promovida por organismos como o Banco Mundial e o Fundo Monetário Internacional (FMI) (ACOSTA, 2015; RIBEIRO, 2001).

O Buen Vivir também se desvencilha da concepção de desenvolvimento sustentável, que se apresentou enquanto alternativa ideológica e utópica no final do século $X X$, com a menor propensão do socialismo de se constituir como alternativa ao capitalismo. Enquanto o Buen Vivir se mostra como alternativa à própria noção de desenvolvimento, o desenvolvimento sustentável visa uma conciliação entre crescimento econômico e preservação ambiental, constituindose em uma noção totalizante e concebendo a natureza, ainda, enquanto um recurso (ACOSTA, 2015; RIBEIRO, 2001).

Essa contraposição ao desenvolvimento sustentável fica mais clara quando se evidencia o caráter biocêntrico do Buen Vivir. O biocentrismo, opondo-se ao antropocentrismo, tem como cerne a noção de que a natureza precisa ser enxergada além dos benefícios que possa trazer aos seres humanos. Assim, de acordo com essa concepção, ela não deve ser vista tendo-se como referência a utilidade que possui à espécie humana, sendo levada em conta a preservação de outras espécies e dos ecossistemas (GUDYNAS, 2011b).

Por fim, a ideia de soberania também pode ser vista como um ponto de divergência entre a teoria marxista e o Buen Vivir. Para Marx, o potencial revolucionário que faz do proletariado o agente da emancipação universal é, justamente, o fato do capital não ter bandeira e, portanto, de sua exploração se dar a nivel global. A transformação social promovida pela revolução proletária só é tão profunda, porque não se dá a nível local, promovendo a dissolução não só da divisão de classes, mas do Estado. 
Já no Buen Vivir, a soberania aparece como um elemento essencial no processo de afirmação identitária dos povos latino-americanos. Isso, porque é por meio dela que tais povos podem se desvencilhar de uma posição de dependência material e subjetiva em relação à Europa, voltando-se para as demandas de seus povos e se desvinculando de padrões de consumo que têm como base uma conduta individualista de busca de riqueza e poder a qualquer custo (ACOSTA,2008, 2010; QUIJANO, 2012).

Além disso, rompe-se com a ideia desenvolvimentista de que antes da justiça social é necessário o crescimento econômico. Não se tem mais por objetivo o crescimento a qualquer custo e a exploração massiva do meio ambiente e de sua população, já que aquele deixa de ser visto como condição para um maior bem-estar futuro (ACOSTA, 2008).

Outra questão é a recuperação do papel do Estado enquanto promotor de ações estratégicas para a superação do capitalismo e das crises que the são características, mas sem que culmine num despotismo burocrático. Propõe-se, assim, que não se deixe de levar em consideração as peculiaridades das perspectivas locais e regionais, já que, sem estas, tais ações poderiam constituise em meras adaptações de modelos em que o Estado continua a desempenhar o papel principal (ACOSTA, 2010)

Em resumo, o Buen Vivir se contrapõe ao materialismo histórico de Marx por não ver o bem-estar humano sob um viés eurocêntrico de desenvolvimento. Ele rompe com a ideia de subordinação da consciência ao plano material, com a concepção de desenvolvimento linear e com a crença no antagonismo de classe como motor da história, propondo, como alternativa, uma visão de mundo fundamentada nas ideias de complementariedade entre as formas de existência, solidariedade enquanto princípio econômico e comunitarismo como fundamento da organização social.

\section{Vida plena e comunismo: alternativas ao sistema capitalista}

Apesar de todos os antagonismos já expostos entre a teoria marxista e o 
Buen Vivir, ambas têm em comum a critica às desigualdades sociais características do modo de produção capitalista, propondo alternativas a esse modelo. Ambas se opõem à continuidade de um sistema que se estrutura na exploração do homem pelo homem, na produção exacerbada de mercadorias e na ausência de sentido de um trabalho que passa a ser direcionado por uma consciência alheia e se fundamenta no estranhamento do homem em relação ao seu meio e a si mesmo.

No Buen Vivir, a alternativa apresentada em relação ao Capitalismo congrega o respeito à diversidade cultural, à soberania dos povos e à natureza. Nessa concepção, a vida alcançaria plenitude na medida em que os saberes deixassem de ser hierarquizados, que o homem buscasse uma relação de complementariedade com as outras formas de existência (mesmo que isso implicasse em menor riqueza material) e que passasse a estruturar suas relações com bases no comunitarismo.

Já na teoria marxista, a superação do capitalismo se concretizaria com a sociedade comunista, onde o homem reestabeleceria sua ligação com seu corpo inorgânico (a natureza) e com os outros homens por meio do fim da propriedade privada dos meios de produção e, consequentemente, da divisão do trabalho e das classes sociais. Nesse contexto, o homem não se apartaria mais de sua vida genérica e passaria a se reconhecer, assim, enquanto ente genérico, que não tem a transformação da natureza condicionada por uma consciência que é alheia à sua e que se reconhece nas relações sociais que estabelece com outros homens (MARX, 1998; 2007).

Desse modo, a emancipação humana se tornaria viável, não havendo a restrição, como nas sociedades burguesas, à emancipação política (que, na verdade, levaria à "[...] redução do homem, por um lado, a membro da sociedade burguesa, a individuo egoísta independente, e, por outro, a cidadão, a pessoa moral") ou aos direitos do homem, tais quais a liberdade, a segurança e a igualdade, os quais estariam associados à concepção de que a sociedade limitaria a autonomia. Em outras palavras, a emancipação humana viabilizada pelo comunismo possibilitaria que o homem enxergasse sua "força própria" como uma 
"força social" e não como algo apartado dela (MARX, 2010, p. 54).

O comunismo, entretanto, só seria passivel de se concretizar quando a indústria convertesse o proletariado em seu "escravo branco", em que a tecnologia chegasse a um nivel de desenvolvimento em que até crianças pudessem ser utilizadas no processo produtivo e em que o salário não assegurasse o mínimo para que tal mão-de-obra pudesse continuar a exercer o seu trabalho, que exigia quase nenhuma qualificação (MARX, 1996). Em outras palavras, o comunismo só se realizaria depois que a classe dominante dentro do Capitalismo não mais possibilitasse o desenvolvimento, mas o entrevasse com a manutenção de uma estrutura social arcaica (MARX, 1998).

Assim, tanto o Buen Vivir quanto a teoria marxista condicionam uma maior justiça social e bem-estar humano à superação do capitalismo. Entretanto, a superação desse sistema fundamenta-se em critérios distintos. No caso do Buen Vivir, a reconfiguração das relações sociais sobre os ideais de solidariedade e harmonia é tida como uma maneira de romper com esse sistema. Já no caso da teoria marxista, a superação do capitalismo só seria alcançada se a oposição entre as classes atingisse seu limite, e, então, através da luta armada, o proletariado se emancipasse da exploração.

\section{Conclusão}

A Teoria Marxista se desenvolveu em um contexto marcado pelas revoluções sociais, em que a grande indústria, ao mesmo tempo em que gerava fascínio por sua capacidade de transformação e domínio da natureza, engendrava horror pelas descrições das condições de trabalho e de vida do proletariado na Europa. Nesse contexto, classificado por Berman (1986) como a segunda fase da modernidade, a produção artística, literária e acadêmica, apesar de ser marcada pela crítica social, refletia a sua ambiguidade por não se desvincular da crença no progresso.

Tendo por pano de fundo essa realidade, a teoria marxista não foi capaz de se desvencilhar desse dualismo. Nela, o desenvolvimento da humanidade não se 
desvincula do seu viés progressista e eurocêntrico, sendo todas as nações dispostas em uma trajetória histórica linear. Essa trajetória, por sua vez, seria marcada pelas contradições sociais, mas culminaria, paradoxalmente, na emancipação de toda a humanidade e no restabelecimento da ligação entre esta e a sua vida genérica.

O Buen Vivir escapa dessa visão linear da história e da hierarquização dos diferentes modos de organização social ao deixar de associar a superação do capitalismo à intensificação das contradições sociais. Aqui, a emancipação humana não se vincula à sua capacidade de submeter a natureza às suas vontades, nem à degradação e exploração de uma classe em prol dos interesses de outra. A vida plena perpassa o equilibrio com todas as formas de existência e tem por base uma sociedade estruturada em relações de complementariedade e solidariedade.

Por fim, cabe destacar o papel dessa concepção de mundo no processo de autoafirmação identitária das nações latino-americanas. A teoria marxista é, em certo sentido, uniformizadora no ideal de desenvolvimento a ser seguido (contemplando no comunismo uma projeção de sociedade futura que possibilitaria que a atividade humana se desvencilhasse dos limites do capital) e de classe encarregada de promovê-lo lo proletariado como classe universalmente oprimida encarregada de promover uma revolução com alcance global).

O Buen Vivir, por sua vez, vê na questão da soberania um elemento-chave na resistência dos povos latino-americanos frente aos padrões culturais e econômicos impostos pelos chamados "países desenvolvidos". Por meio dela é que tais países se tornariam menos economicamente dependentes do contexto externo e teriam condições de formular, a partir do que entendem como sendo mais adequado à sua realidade, o ideal de desenvolvimento que almejam.

Além disso, o Buen Vivir, ao não colocar a Europa como ponto de referência, como modelo de desenvolvimento a ser seguido, rompe-se não só com a tese de desenvolvimento dependente, que relega tais povos a uma posição de subalternidade (enquanto exportadores) no plano econômico, mas 
também com o eurocentrismo, o que torna possivel, por sua vez, a descolonização do saber.

\section{Referências}

ACOSTA, Alberto. Buen Vivir: una oportunidad por construir. Ecuador Debate, $n$. 75. dez. 2008.

Respuestas regionales para problemas globales. In: LEÓN, I. (org.). Sumak Kawsay/ BuenVivir y cambioscivilizatorios.Quito: FEDAEPS, 2010, p. 89-105.

.The BuenVivir as an alternative to development.Some economic and noneconomic considerations.Política y Sociedad - El BuenVivir como alternativa aldesarrollo, vol. 52, núm. 2, 2015, p. 299-330.

BERMAN, Marshall. Tudo que é sólido desmancha no ar: a aventura da modernidade. São Paulo: Companhia das letras, 1986.

CADERMATORI, Daniela M. L.; CADERMATORI, Sergio U. Apontamentos para uma concepção marxista de desenvolvimento e a alternativa do "vivirbien /buenvivir". In: BELLO, E. Direito e marxismo: transformações na América Latina contemporânea. Caxias do Sul: EDUCS, 2014

ENGELS, Friedrich; MARX, Karl. A ideologia alemã. São Paulo: Boitempo, 2007

HEIDEMANN, Francisco G.Do sonho do progresso às políticas de desenvolvimento. In:____; SALM, J. F. (orgs.). Política Públicas e Desenvolvimento - Bases epistemológicas e modelos de análise. Brasília: UnB, 2009 .

GUDYNAS, Eduardo. Buenvivir: germinando alternativas aldesarrollo. America Latina em movimento.n. 492, fev. 2011a.

Tensiones, contradiciones y oportunidades de ladimensión ambiental delBuenVivir. In: FARAH, I.; VASAPOLLO, L(Org.). VivirBien:¿Paradigma no capitalista?. La Paz: CIDES- UMSA y Plural, fevereiro de 2011b, p. 231-246.

LYOTARD, Jean- François. A condição pós-moderna. : José Olympio, 2009.

MARX, Karl. A ideologia Alemã: Critica da mais recente filosofia alemã em seus representantes Feuerbach, B. Bauer e Stirner, e do socialismo alemão em seus diferentes profetas. São Paulo: Boitempo, 2007.

Contribuição à crítica da economia política. São Paulo: Expressão popular, 2008.

Crítica da Filosofia do Direito de Hegel.São Paulo: Boitempo, 2010. 
O Capital: crítica da economia política. São Paulo: Nova Cultural, 1996.

Manuscritos econômico-filosóficos.São Paulo: Boitempo, 2004.

Manifesto do Partido Comunista. São Paulo: Boitempo, 1998.

Sobre a questão judaica. São Paulo: Boitempo, 2010.

QUIJANO, Anibal. "Bienvivir": entre el "desarrollo" y lades/colonialidaddel poder. VientoSur, n. 122, maio de 2012, p. 46-57.

Colonialidade do poder, eurocentrismo e América Latina. In: Edgardo Lander (org). A colonialidade do saber: eurocentrismo e ciências sociais. Perspectivas latino-americanas. ColecciónSurSur, CLACSO, Ciudad Autónoma de Buenos Aires, Argentina. Setembro 2005.

RIBEIRO, Gustavo Lins. Ambientalismo e desenvolvimento sustentado: nova utopia/ideologia do desenvolvimento. Revista de Antropologia. São Paulo, USP, n. 34, 1991, p. 59-101.

TORTOSA, José Maria. Maldesarrollo como Mal Vivir. America Latina em movimento, n. 445, jun. 2009, pp.18-21. 